\title{
THEORETICAL AND METHODOLOGICAL CALCULATIONS OF SOLAR ENERGY RESOURCE POTENTIALS IN THE NORTHERN GARAGUM
}

\author{
Akhmet Pendjiev ${ }^{1}$, and Serdar Nazarov ${ }^{2}$ \\ ${ }^{1}$ Turkmen State Institute of Architecture and Construction \\ ${ }^{2}$ The State Energy Institute of Turkmenistan
}

\begin{abstract}
The urgency of the issue is the development of the Garagum desert, which occupies $80 \%$ of the land resources of Turkmenistan. The aim of the research is to supply the desert regions of the Garagum with energy using solar energy technologies and installations. The research task - to determine the solar-energy resource potential using innovative methods of calculation in the design, creation and implementation of efficient solar energy technology and equipment. Methodology. To determine the gross, technical, economic and ecological potential, the natural and climatic conditions of the Northern Garagum are taken into consideration. Research methodology - used meteorological data, processed by laws of physics and mathematical calculation methods for thermal and photoelectric converters. Research results. The theoretical and methodological calculations of the gross, technical, economic and environmental potentials of solar energy are estimated, the energy efficiency of solar radiation is determined, and the optimal solar collector inclination angles for the Northern Garagum are calculated. Discussion and conclusion. As a result of the research, the resource potentials of solar energy were obtained, converted into thermal and electrical energy, $\mathrm{kW} \cdot \mathrm{h} / \mathrm{m}^{2}$ per year: gross - 1844.6; technical - 1227.58 and 244.85 ; economic -1354.58 and 270.25. Environmental potentials, $\mathrm{CO}_{2}, \mathrm{~kg} /$ year: 784.96 and 156.6. The most effective for the use of solar collectors in the Northern Garagum for months of the year with an angle of inclination is: 60 degrees January, February, November, December; $45^{\circ}$ - March, October; $30^{\circ}$ - from April to September.
\end{abstract}

\section{Introduction}

At the present stage of scientific and technological development, modern Turkmenistan is a dynamically developing state with the richest natural resources, infrastructural and human potential. Tasks on the stable development of the economy of Turkmenistan are based on the employment of the modern and innovative technologies in all the branches of the production $[1,2]$.

$80 \%$ of the territory of Turkmenistan is occupied by the Karakum Desert and the problem of its development and control of the desertification is one of the most important problems of the country. Utilization of the solar energy can play a crucial role in the solution of the problem of energy and water supply for the development of the desert. Extending power lines is unreasonable because of the low density of the population and their high economic costs.

The problem of water supply of the territory can partially be solved by the utilization of the underground waters of the desert, whose capacity is about $80 \mathrm{~km}^{3}$, but they are located in the various depths from 5 to 300 meters and with various mineralization degree. The other way is to utilize "Altyn Asyr Lake", an operating hydraulic structure, based on the lead-in of all the drainage water of all the velayats (regions) of Turkmenistan [2].

The problem of water lift from these depths can be solved by the employment of the solar water-lifting machinery. Solar energy resources of the country through its territory is about $4 \cdot 10^{15}$ kilojoule, or in the equivalent of $1,4 \cdot 10^{9}$ ton of fuel equivalent a year $[3,6,12]$.

For the development, creation, introduction of the innovative solar energy systems and electric and heat energy supply of the Karakum desert population, it is necessary to conduct a complex of theoretical, experimental research of all the constituent components of the power installation; to determine optimal design philosophy and maximum energy capacity of the system. For the construction and putting into operation of the solar energy systems, it is necessary to compile design estimates. Existing engineering calculations are not exactly enough for the calculation of the technical and economic assessment in the desert zone of Turkmenistan, therefore the solution of these problems is highly actual $[1-4,6,8,12]$. 


\section{Degree of the theme development}

Much progress is achieved by the Turkmen scientists in the scientific-research works on the solar energy utilization. Requirements for the quality of the energy installations and creation of the progressive energy efficient constructions are highly increasing in the modern world. Therefore it is necessary to treat scientific fundamentals of the progressive designing, engineering and technological development of the solar power engineering. A complex of theoretical, calculationanalytical and experimental investigations is the scientific fundamental of the modern and perspective solar power engineering. It is based on the general principles of the fundamental science, and scientific fundamentals of the innovative technique and technology, whose final purpose is to solve concrete production tasks while manufacturing solar power installations in desert zone of the Karakum.

For the fulfillment of the above mentioned requirements, scientifically substantiated and systematized innovative methods and technologies were used in the given work. Resource gross, technical, economic and ecological potentials were theoretically, practically and experimentally investigated with the consideration of nature and climate conditions of the Karakum desert zone [1,2].

The article contains the theoretical and methodological calculations of gross, economically and environmentally potential of solar energy, determined the effectiveness of the Energy flow and solar radiation and inclination angle of solar collector for Northern Garagum.

The Northern Garagum Desert is represented as a set of areas, or zones, in each of which the intensity of the incoming solar radiation and the Earth albedo, as well as geographic, climatic and weather conditions are similar throughout the entire area of the zone. The northern Garagum desert is divided into the following zone: in Karabogaz region; Garagum behind Unguz; delta of the Amu Darya; Ustyurt. Area Northern Garagum has a linear length of $600 \mathrm{~km}[1-3$, $9,13]$.

\section{Methodology and methodology of determination}

To determine gross, technical, economic and environmental potentials of part of Northern Garagum following data are taken into account for a year. They are long-term long-term average annual influx of solar energy per unit horizontal surface in i-th month of the year, $\mathrm{kW} \cdot \mathrm{h} /\left(\mathrm{m}^{2}\right.$. month $)$; average long-term arrival of the direct flow of solar energy per unit of horizontal surface in the i-th month of the year, $\mathrm{kW} \cdot \mathrm{h} /\left(\mathrm{m}^{2}\right.$. month $)$; term average arrival diffuse solar energy at unit horizontal surface in i-th month of the year with a cloudless sky, $\mathrm{kW} \cdot \mathrm{h} /\left(\mathrm{m}^{2}\right.$. month); empirical duration of sunshine for the area during the $\mathrm{i}$ - th of the month, hours / year; astronomic possible sunshine duration for the area in the i-th month, h / year [3, 7 - 9, 13].

\subsection{Method for determining the gross potential of solar energy}

The gross capacity of the solar energy of the region mean long-time average annual of total solar energy falling on the northern area of Garagum in one year.

The region is represented as a set of areas, or zones, in each of which the intensity of the incoming solar radiation and the albedo of the Earth, as well as geographic, climatic and weather conditions are homogeneous throughout the area of the zone. The number of zones in the region, their position and area are recorded in the table $[8,10,13]$.

In accordance with the determination of the gross potential according to the formula, it is necessary to obtain data on the monthly arrival of solar energy on the horizontal surface $E_{i}(i=1,2, \ldots, 12)$.

The calculated data are entered into tables at the values of which $E_{i}$ during the year by months $i=1-$ 12 .

The average parameter of the inclination angle of direct solar radiation to the normal $\langle\cos \theta\rangle$ and the monthly arrival of direct solar energy on a normally oriented surface for 10 hours (from 7 to 17 hours) $[3,6]$.

$$
E_{O P i}=\frac{E_{\Pi i}}{\langle\cos \theta\rangle}=\frac{(1-\varepsilon) E_{i}}{\langle\cos \theta\rangle}=2187.95 \mathrm{~kW} \cdot \mathrm{h} /\left(\mathrm{m}^{2} \cdot \text { month }\right),(1)
$$

where $E_{O P i}, \mathrm{~kW} \cdot \mathrm{h} /\left(\mathrm{m}^{2} \cdot \mathrm{month}\right)$, is long-time average annual influx of solar energy per unit of horizontal surface in the $i$ - th month of the year with a cloudless sky; $E_{n i}, \mathrm{~kW} \cdot \mathrm{h} /\left(\mathrm{m}^{2} \cdot\right.$ month), is long-time average annual influx of the direct flow of solar energy per unit of horizontal surface in the $i$ - th month of the year; $E_{i}, \mathrm{~kW} \cdot \mathrm{h} /\left(\mathrm{m}^{2} \cdot\right.$ month $)$, is long-time average annual influx of solar energy per unit of horizontal surface in the $i$ - th month of the year; $\varepsilon$ is the coefficient of radiation $[4,6-8,10,13]$.

The total input of solar energy per unit of horizontal surface per year for 10 hours a day (7-17 hours), E, turns out to be equal

$$
E=\sum_{i} E_{i}=1895.9 \mathrm{~kW} \cdot \mathrm{h} /\left(\mathrm{m}^{2} \cdot \text { year }\right),
$$

the gross potential of the Northern Garagum per square meter is

$$
W_{B}=E S=1844.6 \mathrm{~S} \mathrm{~kW} \cdot \mathrm{h} / \text { year, }
$$

where $\mathrm{S}, \mathrm{m}^{2}$, is the area.

\subsection{Methodology for determining the technical potential of solar energy in the region}

The technical potential of the region's solar energy is long-time average of total energy that can be obtained for the region from solar radiation within one year at the 
current level of development of science and technology and compliance with environmental standards.

The technical potential of solar energy is the sum of the technical potentials of thermal energy and electrical energy obtained by the corresponding conversion of solar radiation $[6-10,13,15,16]$.

Technical potential of thermal energy from solar radiation. Initial data: hot water temperature $\mathrm{T}=$ $60{ }^{\circ} \mathrm{C}$; the value of the parameters of solar thermal collectors, characterizing the modern technical level: $F(\tau \alpha)=$ $0.9 ; F U_{L}=$ $0,005 \mathrm{~kW} /\left(\mathrm{m}^{2} \cdot{ }^{\circ} \mathrm{C}\right)$; experimentally determined monthly average temperatures $T_{O i}$ and declination angles $\delta$ for $i=1,2,3, \ldots, 12[4,8-11]$.

The calculated values of the duration of sunshine during the $i$-th month $t_{C i}, \mathrm{~h} /$ month, the number of clear and semi-cloudy hours, the duration of the working time $t_{P i}, \mathrm{~h} /$ month, as well as monthly potentials per unit of the allotted area during working hours ( from 7 am to $5 \mathrm{pm})$,

$$
\begin{aligned}
\frac{W_{T T i}}{S_{T}}=E_{i} F & {\left[(\tau \alpha)-U_{L}\left(T-T_{O i}\right) \cos (\phi-\delta) \frac{t_{P i}}{E_{i}}\right]=} \\
& =1227.58 \mathrm{~kW} \cdot \mathrm{h} / \text { year }
\end{aligned}
$$

where $S_{T}=k_{T} q S$ is the area for solar thermal installations and, obtained using the values of $E_{i}$, for the sunniest months of the year.

In the autumn-winter months (October - February), the use of collectors with the presented technical parameters to obtain hot water with a temperature $T_{G}=60{ }^{\circ} \mathrm{C}$, i.e. the corresponding $W_{T T i}$ are equal to zero.

Summing up over all months determines the potential of solar thermal energy $W_{T T}$ for 10 hours a day (7-17 hours):

$$
W_{T T}=1227.58 S_{T}, k W \cdot h / \text { year }
$$

where $S_{T}, \mathrm{~m}^{2}$, is the area allocated for solar thermal installations.

Technical potential of electricity from solar radiation. Basic

data:

to $\mathrm{F}=1$ to $\mathrm{T}$; the values of the parameters of photovoltaic solar cells, characterizing the modern technical level: $\alpha=$ $0.97 ; \eta_{1}=0.13 ; \chi=0.004 \mathrm{~K}^{-1} ; \mathrm{T}_{1}=298 \mathrm{~K} ;\langle\lambda\rangle=40 \mathrm{~W}$ $/\left(\mathrm{m}^{2} \cdot \mathrm{K}\right)[4,1,1.13]$.

The calculated values of the average monthly operating temperature $T_{i}$,

$$
T_{i}=\frac{\frac{E_{i}}{t_{P i}}\left[\alpha-\eta_{1}\left(1+\chi T_{1}\right)\right]+\langle\lambda\rangle T_{O i}}{\langle\lambda\rangle-\frac{E_{i}}{t_{P i}} \eta_{1} \chi}
$$

using the values of $T_{O i}, E_{i}$. The calculated values of the monthly technical potentials per unit of the allotted area,

$$
\frac{W_{T \Phi \mathrm{i}}}{\mathrm{S}_{\Phi}}=E_{i} \eta_{1}\left[1-\chi\left(\mathrm{T}_{\mathrm{i}}-\mathrm{T}_{1}\right)\right]=244.85 \mathrm{~kW} \cdot \mathrm{h} / \text { year }(7)
$$

where $S_{\Phi}=k_{\Phi} \cdot q \cdot S, \mathrm{~m}^{2}$, is the area allotted for solar photovoltaic installations $[10,11,13]$.

Summation over all determines the potential $W_{T \Phi}$ :

$$
W_{T \Phi}=244.85 \cdot S_{\Phi}, k W h / \text { year }
$$

Total technical potential of solar energy. The value of the total technical potential of solar energy is equal to:

$$
\begin{aligned}
& W_{T}=W_{T T}+W_{T \Phi}=1227.58 \cdot S_{T}+244.85 \cdot S_{\Phi}= \\
= & {\left[1227.58 k_{T}+244.85\left(1-k_{T}\right)\right] q S, k W \cdot h / \text { year } }
\end{aligned}
$$

It should be noted that $W_{T T}$ represents energy in the form of heat and $\mathrm{W}_{T \Phi}$ represents energy in electrical form. Graphic images in the form of a histogram of energy indicators of gross, technical potentials converted into thermal and electrical energy during the year in the Northern Garagum are shown in Figure 1 .

\subsection{Methodology for determining the economic potential of solar energy in the region}

The economic potential of solar energy in the region is the value of the annual production of thermal and electrical energy in the region from solar radiation, the receipt of which is economically justified for the region at the current level of prices for energy obtained from traditional sources, and compliance with environmental standards $[5,8-10,13]$.

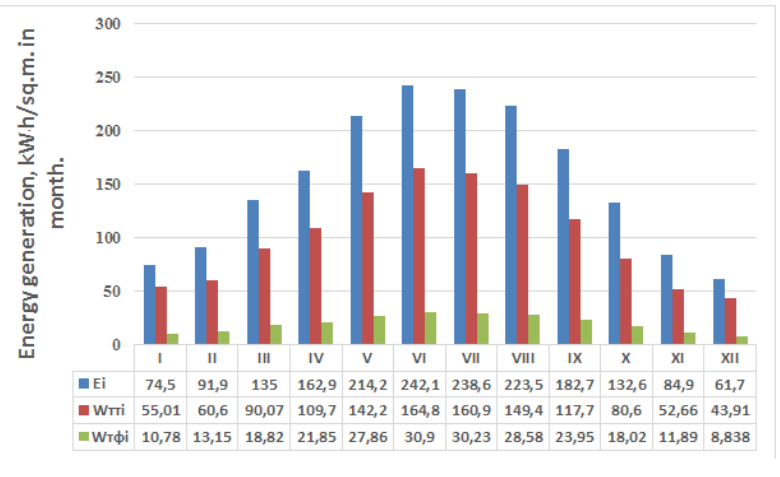

Fig. 1. Histogram of the energy indicators of the gross (Ei) and technical potentials, converted into heat (Wtti) and electric energy $\left(\left(\mathrm{Wt}_{\phi \mathrm{i}}\right)\right)$ during a year in the Northern Karakum.

The procedure for calculating the economic potential of solar energy. Recorded the initial data: hot water temperature $T_{G}=60^{\circ} \mathrm{C}$; cold water temperature $T_{X}=15{ }^{\circ} \mathrm{C}$; the values of the parameters of solar collectors, characterizing the technical level: $F(\tau \alpha)$ $=0.9 ; F \cdot U_{L}=0.005 \mathrm{~kW} / \mathrm{m}^{2} \cdot{ }^{\circ} \mathrm{C}$; norm m $=100 \mathrm{~kg} /$ (person · day); installation cost $C=400 \$ / \mathrm{m}^{2}{ }^{2} ; T_{C_{\Pi}}=15$ years; heat capacity of water with $c_{P}=4.17 \mathrm{~kJ} /$ $\left(\mathrm{kg}^{\circ} \cdot \mathrm{C}\right)$; values of specific parameters: $C_{T}, C_{\Pi}$, $I_{E K}$; cost factors: $r_{P}, r_{e}, r_{T e}$; the needs of the industry for thermal energy $Q_{n T i}(i=1,2, \ldots, 12)$; the number of people in need of $N_{T}$.

Using the values of the parameters of the influx of solar energy and the outside temperature, obtained in the 
previous sections, are sequentially calculated: $\left\langle\cos \xi\right.$ ), $E_{H i}$ and $V_{T i}$ for $i=1,2, \ldots, 12[11,13]$.

Summation for all months is determined by $E_{H}, V_{T}(2.34)$ and $V_{T K P}$ are calculated. By analyzing the conditions of the potentials in the Northern region of the Garagum, the area of determining the economic potential $W_{E T}$ is determined . Calculate $Q_{B T}$ and $Q_{T}$, and the excess capacity $\Delta W_{E T}$.

The determination of the economic potential is carried out under the condition that the solar thermal collectors are stationary oriented at an angle of inclination to the horizon $\beta$. The calculation of the economic potential of thermal energy is carried out according to the formula

$$
W_{\ni T}=\sum_{i} W_{\ni T i}, i=1,2, \ldots, 12,
$$

where $i=1,2, \ldots, 12$, summation is performed over all months of the year.

The economic potential of the $i$-th month is determined by the expressions:

$$
W_{E P i}=V_{T i} \cdot S_{Э T}
$$

where

$$
\begin{aligned}
V_{T i} & =E_{H i} \cdot F\left[(\tau \alpha)-U_{L}\left(T-T_{O i}\right) \frac{t_{C i}}{E_{H i}}\right]= \\
& =1354.58 \mathrm{~kW} \cdot \mathrm{h} /\left(\mathrm{m}^{2} \cdot \text { year }\right)
\end{aligned}
$$

Determination of the economic potential of electricity from solar radiation. The calculation of the economic potential of electricity is carried out in the same way as in the above option.

The economic potential of the $i$ - th month is determined by the expression:

$$
\begin{gathered}
W_{\ni \Phi i}=V_{\Phi i} \cdot S_{\ni \Phi}, \\
V_{\phi i}=E_{\phi i} \eta_{1}\left[1-\chi\left(\mathrm{T}_{\mathrm{i}}-\mathrm{T}_{1}\right)\right]= \\
270,25 \mathrm{kWt} \cdot \mathrm{h} /\left(\mathrm{m}^{2} \cdot \text { year }\right) .
\end{gathered}
$$

where: $V_{\Phi i}, \mathrm{~kW} \cdot \mathrm{h} /\left(\mathrm{m}^{2} \cdot\right.$ month $)$, - the volume of energy generation by a unit of the area of the solar battery in the $i$ - th month is equal to $270.25 \mathrm{~kW} \cdot \mathrm{h} /$ $\left(\mathrm{m}^{2} \cdot\right.$ year $) ; E_{\Phi i}, \mathrm{~kW} \cdot \mathrm{h} /\left(\mathrm{m}^{2} \cdot\right.$ month $)$, - the long-term average influx of solar energy per unit surface of the solar battery in the $i$ - th month of the year is $1354.58 \mathrm{~kW}$ $\mathrm{h} /\left(\mathrm{m}^{2}\right.$. year $) ; \mathrm{S}_{E \Phi}, \mathrm{m}^{2}$ - economically feasible area installed solar battery [8-10] .

The total economic potential of solar energy is obtained by summing the potentials of thermal and electrical energy:

$$
W_{\ni}=W_{\text {ЭТ }}+W_{\ni \Phi}=1354.58 S t+270.25 S_{\Phi} .
$$

Figure 2 shows the specific volume of energy generation per unit area of a thermal collector and a photovoltaic module by months of the year, $\mathrm{kW} \cdot \mathrm{h} /$ $\left(\mathrm{m}^{2} \cdot \mathrm{month}\right)$.

Thus, the economic potential of thermal energy from solar radiation in the region $W_{E T}$ has a growing dependence on the value of the annual volume of energy removed from the unit surface of the thermal collector, which is determined by three parameters. They are the critical value of the specific energy generation, the economic parameter of the regional industry's need for energy, and the price parameter industrial production. This dependence is in fact the same for any new energy source replacing traditional fuel, including both thermal energy and electric energy from solar radiation.

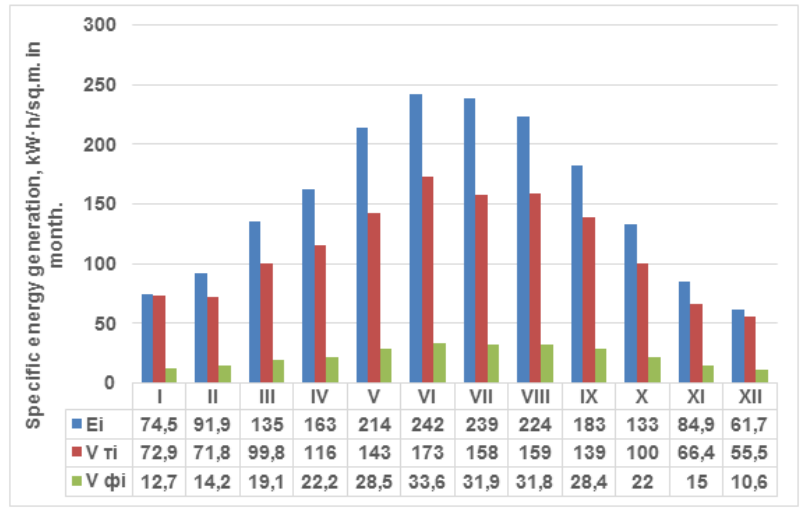

Fig. 2. Specific conversion of energy into heat $(\mathrm{Vt})$ and electrical (VФ) in the Northern Karakum from $1 \mathrm{~m}^{2}$ by months of the year.

\subsection{Environmental potential from generating solar energy into thermal and electricity energy}

The ecological potential of solar energy is a part of the technical potential, the transformation of which into usable ecological energy is advisable at a given level to reduce harmful emissions into the environment from fossil, fossil fuels when converting thermal, electrical energy and other types of energy from equipment, installations, stations and transport funds and other pollutants.

The expressions that determine economic efficiency do not take into account the impact of the introduced installations on the environment, on the social conditions of human life and activities, which is generally defined as environmental conditions. Solar energy in comparison with traditional energy has an important advantage, concluded in the possibility of ecological purity of the used installations, and in some cases - opportunities to improve the environmental situation.

The ecological potential of solar energy is the sum of the economic potentials of thermal energy and electrical energy obtained by the corresponding conversion of solar radiation $[7,8]$.

One of the accounting instrument having influence on the introduced energy sources on the ecology of the region can be the introduction into the unit cost of the received energy of the regional environmental factor of the source. It takes into account the relative costs of 
compensating for the harmful consequences of the input of a unit of energy of one or another source in the region. If coefficient of regional ecological factor is $>1$ for the source, then it leads to deterioration of ecological conditions of the region. If coefficient of regional ecological factor is $<1$ for the source, then it leads to improvement of ecological conditions of the region. Figure 3 shows the results of reducing anthropogenic loads from one square meter from the conversion of solar energy into heat and electricity.

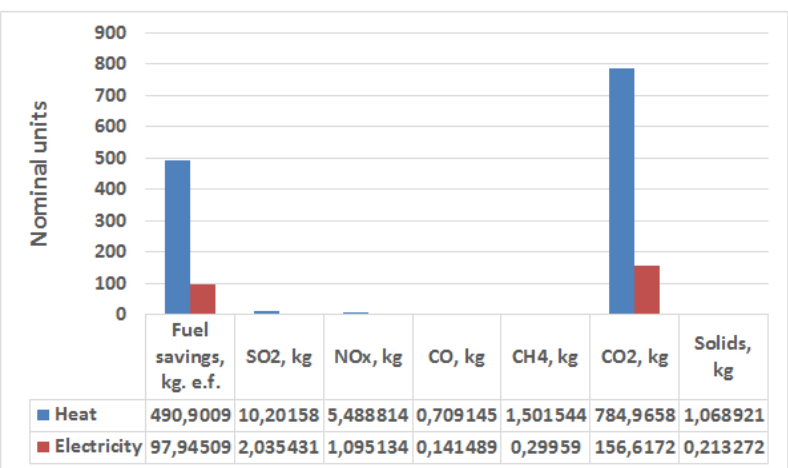

Fig. 3. Histogram of the heat (blue) and electric (red) energy, and the possibilities of reducing the emission of various harmful substances into the environment during a year.

Expected result. Expected possibilities of emission reduction of various harmful substances into the environment in the Northern Garagum by using solar energy will be:

- with an annual generation from 1 sq. $\mathrm{m}$ thermal $1227.8 \mathrm{~kW} \cdot \mathrm{h} /$ year, fuel savings $490.9 \mathrm{~kg}$ of equivalent fuel/year, reducing emissions: sulfur dioxide $\mathrm{SO}_{2}$ - 10,2,0; nitrogen oxide $\mathrm{NO}_{\mathrm{x}}-5.48$; carbon monoxide $\mathrm{CO}-0.71$; methane $\mathrm{CH}_{4}-1.5$; carbon dioxide $\mathrm{CO}_{2}-784.96$; solids - $1.0 \mathrm{~kg}$ / year .

- with an annual generation from 1 sq. m 270.25 $\mathrm{kW} \cdot \mathrm{h}$ / year, fuel consumption saving $97.9 \mathrm{~kg}$ of fuel equivalent / year, reduction of emissions: sulfur dioxide $\mathrm{SO}_{2}-2.0$; nitrogen oxide $\mathrm{NO}_{x}-1.1$; carbon monoxide $\mathrm{CO}-0.1$; methane $\mathrm{CH}_{4}-0.2$; carbon dioxide $\mathrm{CO}_{2}-156.6$; solids $-0.2 \mathrm{~kg} /$ year [ $7,8,13$ ].

\subsection{Empirical expression of potential of solar energy in Northern regions of Turkmenistan}

Conversion of solar energy using photoconverters depends on the gross technical potential of solar radiation. In our calculations, we used meteorological data taken from reference books on climate [6 - 10, 13].

Processing local meteorological data, expanding to Fourier series, we obtain the forecast empirical formula of an average output of photo converter, in $\mathrm{kW} /$ $\mathrm{m}^{2}$ on the months of the year, for the Northern Garagum :

gross potential

$$
\begin{gathered}
I=466.25+317.8 \cos (0,26-0,058)+ \\
+24 \cos (0,52+1,0)++11.2 \cos (0,78-0,244),
\end{gathered}
$$

where $I$ - is the average solar radiation, $\mathrm{kW} / \mathrm{m}^{2} ; \tau$ months of the year.

In a logarithmic form, the expression for solar radiation (Y), respectively, can be written:

$$
\begin{gathered}
Y=83,8245 \cdot \ln (x)+375,34 ; \\
I=233.12+158.9 \cos (0.26-0.058)+ \\
+12.0 \cos (0.52+1.0)++5.6 \cos (0.78-0.244) .
\end{gathered}
$$

Using the technical potential of solar energy for a photovoltaic converters with efficiency of 10 to $12 \%$ ( in the calculations was used the average $11 \%$ ) and by several mathematical operations and converting the emissions of $\mathrm{CO}_{2}$ - we obtain empirical relationship reduction of $\mathrm{CO}_{2} \mathrm{gr} . / \mathrm{m}^{2}$ formula as follows:

$$
\begin{gathered}
I=51.28+34.96 \cos (0.26-0.058)+ \\
+2.64 \cos (0.52+1.0)++\cos (0.78-0.244) .
\end{gathered}
$$

\subsection{Determination of the optimal inclination angle of solar modules in the Northern Garagum}

The calculation results for determining the optimal inclination angle of solar modules in the Northern Garagum, taking into account the actual generation of solar energy, includes the determination of the total flow of solar energy onto the inclined surface for a certain period of time (for example, for a month throughout the year) at various angles of inclination by integrating over time. Calculations show the most effective value $\beta=60^{\circ}$ for January, February, November, December; $\beta=30^{\circ}$ from April to September ; $\beta=45^{\circ}$ - March, October [6,13-16].

$$
\begin{aligned}
E_{\Phi i}= & E_{H i}=E_{\Pi i} \frac{\omega_{m}}{\omega_{S}} \frac{\langle\cos \xi\rangle}{\langle\cos \theta\rangle}+E_{\text {Дi }} \frac{1+\cos \beta}{2}+ \\
& +\rho\left(E_{\Pi i}+E_{\not i}\right) \frac{1-\cos \beta}{2},
\end{aligned}
$$

$E_{m i}$ and $E_{m i}$, as well as $\langle\cos \theta\rangle$, where $\langle\cos \theta\rangle$ is the average parameter of the inclination angle of influx of direct solar radiation on a normally oriented surface; $\langle\cos \xi\rangle$ - angular parameter, is found by the formula:

$$
\langle\cos \xi\rangle=\cos (\varphi-\beta) \cos \delta \frac{\sin \omega_{m}}{\omega_{m}}+\sin (\varphi-\beta) \sin \delta,
$$

and for each month has the value $\beta=\varphi-\delta$; where $E_{n i}$ is the average long-term influx of the direct flow of solar energy per unit of horizontal surface in the $i$-th month of the year, $\mathrm{kW} \cdot \mathrm{h} /\left(\mathrm{m}^{2} \cdot \mathrm{month}\right) ; E_{n i}$ - average long-term influx of dissipated solar energy per unit of horizontal surface in the $i$ - th month of the year, $\mathrm{kW} \cdot \mathrm{h} /$ ( $\mathrm{m}^{2} \cdot$ month); $\rho$ is the reflection coefficient (albedo); $\theta$ is the angle between the directions of the zenith and the Sun (the angle of incidence on the horizontal surface); $\xi$ is the angle between the direction to the Sun and the 
normal to the inclined surface (angle of incidence on the inclined surface), oriented to the south; $\delta$ is the declination angle, i.e. the angular position of the Sun at solar noon relative to the equatorial plane; $\varphi$ is the latitude of the area; $\omega$ is the hourly angle of the Sun's motion, equal to 0 at solar noon; every hour of time $t$ corresponds to $15^{\circ}$ longitude, and the values of the hour angle before noon are considered positive; $\beta$ is the angle of inclination to the horizon $[4,6,10,14]$.

\section{Conclusion}

1. Based on theoretical studies and methodological calculations of solar - energy resources, taking into account the intensity of solar radiation, albedo, geographical, climatic and negative weather conditions, the energy potentials per 1 square meter of the Northern Territory of Turkmenistan are as follows: gross potential - $1895.9 \mathrm{~kW} \cdot \mathrm{h} / \mathrm{m}^{2}$ year; Technical potential conversion into thermal energy $-1227.58 \mathrm{~kW} \cdot \mathrm{h} / \mathrm{m}^{2}$ year, into electrical energy $-244.85 \mathrm{~kW} \cdot \mathrm{h} / \mathrm{m}^{2}$ annually.

2. Feasibility and theoretical calculations of the economic potential will allow to make a feasibility study in the construction of solar-power stations, installations, structures for implementation will enable saving of fossil fuels by the conversion into heat $1354.58 \mathrm{~kW} \cdot \mathrm{h} /$ year; into electrical energy $270.25 \mathrm{~kW} \cdot \mathrm{h} /$ year.

3. The expected ecological potential of reducing emissions of various harmful substances into the environment in the northern territories of Turkmenistan by using a solar photovoltaic stations will be: with an annual output from 1 sq. m. $244.85 \mathrm{~kW} \cdot \mathrm{h} /$ year, fuel consumption saving $97.94 \mathrm{~kg}$ of equivalent fuel/year, reducing emissions: sulfur dioxide $\mathrm{SO}_{2}-2.03$; nitrogen oxide $\mathrm{NO}_{\mathrm{x}}-1.09$; carbon monoxide $\mathrm{CO}-0.141$; methane $\mathrm{CH}_{4}$ 0.299; carbon dioxide $\mathrm{CO}_{2}$ - 156.61 ; solids - 0.213 $\mathrm{kg} /$ year; by conversion of thermal energy - 1227.58 $\mathrm{kW} \cdot \mathrm{h} /$ year, fuel savings $490.9 \mathrm{~kg}$ of equivalent fuel /year, reducing emissions $\mathrm{SO}_{2}$ 10.20; $\mathrm{NO}_{\mathrm{x}} 5.48 ; \mathrm{CO} \quad 0.709 ; \mathrm{CH}_{4}-1.50 ; \mathrm{CO}_{2}$. 784.96; solids - $1.068 \mathrm{~kg} /$ year.

\section{References}

1. Berdimuhamedov G.M. State regulation of the social and economic development of Turkmenistan. // Volume 1. A .: Turkmen State Publishing Service, 2010. - $450 \mathrm{p}$.

2. Berdimuhamedov G.M. Turkmenistan on the way to achieving the Sustainable Development Goals. - A.: Turkmen State Publishing Service, 2018 .- 465 p.

3. The use of solar energy / Under general. ed. L.E. Rybakova. - Ashgabat: Ylym, 1985 .-- 280 p.

4. D.S. Strebkov . Fundamentals of solar energy. Ed. Doctor of Technical Sciences Bezrukikh P.P. M.: SAM Polygraphist. 2019.-326 p.

5. Livshits S.A., Gareishina A.A. Economic prospects of solar energy in Russia: prospects and development problems Scientific aspect . 2017. No. 4-1 . S. 159-162.

6. Scientific - applied reference book on the climate of the USSR. Series 3, parts 1-16, no . - L . Gidromethioizdat, 1989 .-- 502 p.

7. A.M. Pendzhiev, Basics of GIS in the Development of Renewable Energy. Germany : LAP LAMBERT Academic Publishing, 2017 .-- 308 p . ISBN 978620-2-01229-4.

8. Vissarionov, V.I. Solar energy: textbook for universities / V.I. Vissarionov , G.V. Deryugin , V.A. Kuznetsova, N.K. Malinin; under total. ed. IN AND. Vissarionov . - M $\therefore$ Publishing house MEI, 2008 .-- 276 p.

9. Bayramov R.B., Ushakova A.D. Solar water heating installations. - Ashgabat: Iz-vo Ylym , 1987. - 168 p.

10. A.M. Pendzhiev, N.G. Astanov . Investigations of the electrical parameters of a solar PV module for the use of pasture farms in the southeastern Garagum, Alternative energy and ecology, No. 5. pp. 26-32, 2011.

11. Yu.D. Arbuzov, V.M. Evdokimov. Photovoltaic Basics. -M .: GNU VIESH, 2012.- 292 p.

12. Vankov Yu.V., Zapolskaya I.N., Izmailova E.V., Zagretdinov A.R., Plotnikova L.V. Reducing energy consumption when switching to hot water supply from individual heating points / Bulletin of Kazan State Power Engineering University . T. 2019. 11. number 1 (41). S. 19-27.

13. Strebkov D.S., Pendzhiev A.M., Mamedsakhatov B.D. Development of solar energy in Turkmenistan: monograph / D.S. Strebkov, A.M. Pendzhiev, B.D. Mamedsahatov . - M .: GNU VIESH, 2012.- 498 p.

14. K. Ya. Kondratyev, Z. I. Pivovarova. Radiation regime of inclined surfaces. - L .: Gidrometeoizdat , 1978 .-- $215 \mathrm{p}$.

15. Methodology for calculating the power of solar power plants / G.P. Okhotkin , / / Bulletin of the Chuvash University, 2013, issue No. 3, p. 226.

16. Solar panels. Insolation tables for calculating FES. Access mode: http://www.solbat.su/meteorology/insolation free (Date of access: 05/05/2016/. 